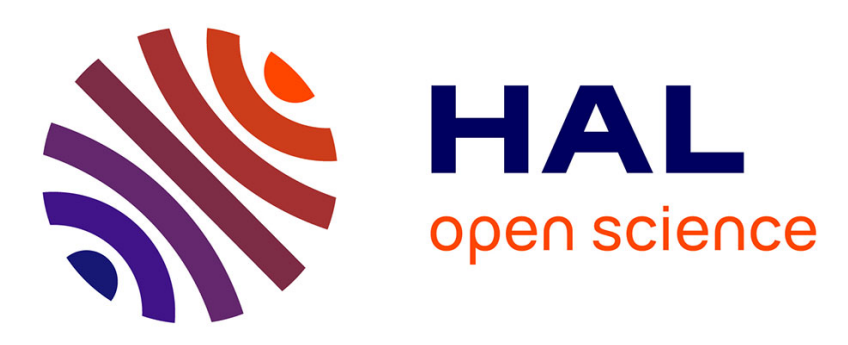

\title{
The more, the merrier? Numerical strength versus subgroup distinctiveness in minority groups
}

Andrew G. Livingstone, Russell Spears, Antony S.R. Manstead, Martin

Bruder

\section{- To cite this version:}

Andrew G. Livingstone, Russell Spears, Antony S.R. Manstead, Martin Bruder. The more, the merrier? Numerical strength versus subgroup distinctiveness in minority groups. Journal of Experimental Social Psychology, 2011, 10.1016/j.jesp.2011.03.012 . hal-00981129

\section{HAL Id: hal-00981129 \\ https://hal.science/hal-00981129}

Submitted on 21 Apr 2014

HAL is a multi-disciplinary open access archive for the deposit and dissemination of scientific research documents, whether they are published or not. The documents may come from teaching and research institutions in France or abroad, or from public or private research centers.
L'archive ouverte pluridisciplinaire HAL, est destinée au dépôt et à la diffusion de documents scientifiques de niveau recherche, publiés ou non, émanant des établissements d'enseignement et de recherche français ou étrangers, des laboratoires publics ou privés. 


\section{Accepted Manuscript}

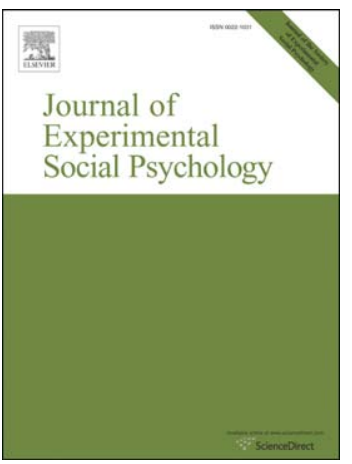

The more, the merrier? Numerical strength versus subgroup distinctiveness in minority groups

Andrew G. Livingstone, Russell Spears, Antony S.R. Manstead, Martin Bruder

PII:

S0022-1031(11)00075-8

DOI:

doi: 10.1016/j.jesp.2011.03.012

Reference:

YJESP 2643

To appear in: Journal of Experimental Social Psychology

Received date: 13 August 2010

Revised date: $\quad 28$ January 2011

Please cite this article as: Livingstone, A.G., Spears, R., Manstead, A.S.R. \& Bruder, M., The more, the merrier? Numerical strength versus subgroup distinctiveness in minority groups, Journal of Experimental Social Psychology (2011), doi: 10.1016/j.jesp.2011.03.012

This is a PDF file of an unedited manuscript that has been accepted for publication. As a service to our customers we are providing this early version of the manuscript. The manuscript will undergo copyediting, typesetting, and review of the resulting proof before it is published in its final form. Please note that during the production process errors may be discovered which could affect the content, and all legal disclaimers that apply to the journal pertain. 
Running head: STRENGTHENING IDENTITY IN MINORITY GROUPS

The more, the merrier?

Numerical strength versus subgroup distinctiveness in minority groups

Andrew G. Livingstone ${ }^{1}$, Russell Spears ${ }^{2}$, Antony S. R. Manstead ${ }^{2}$, and Martin Bruder ${ }^{3}$

${ }^{1}$ Psychology, School of Natural Sciences, University of Stirling, Scotland, UK

${ }^{2}$ School of Psychology, Cardiff University, Wales, UK

${ }^{3}$ Department of Psychology, University of Konstanz, Germany

Correspondence should be addressed to Andrew Livingstone, Psychology, School of Natural Sciences, University of Stirling, Stirling, FK9 4LA, Scotland, UK

Email can be sent to A.G.Livingstone@stir.ac.uk

Acknowledgements:

This research was made possible by support from the Leverhulme Trust (ECF/2007/0050) and the ESRC (RES-148-25-0014), and forms part of the ESRC Identities and Social Action Programme. We are grateful to Matt Leighfield and Neil Williams for their technical support, and to Nicole Tausch for helpful comments and suggestions relating to Study 1. 
Running head: STRENGTHENING IDENTITY IN MINORITY GROUPS

The more, the merrier?

Numerical strength versus subgroup distinctiveness in minority groups 
The more, the merrier?

Numerical strength versus subgroup distinctiveness in minority groups

\begin{abstract}
Evidence attests to the efforts made by minority groups to defend and promote 'distinctive' attributes that potentially define the ingroup. However, these attributes are often only available to a prototypical minority within the minority category. In two studies we tested the hypothesis that, under certain conditions, large projected increases in the numerical strength of a 'distinctive' attribute (emotional intelligence in Study 1; ingroup language in Study 2) within a minority category can paradoxically evoke less-than-positive reactions from those who already have the attribute. Findings confirmed that while a large projected increase in the numerical strength of a 'distinctive' attribute was viewed positively when the comparative context focused on the inter-category relation with a majority outgroup, this increase was viewed less positively, and as undermining their own identity, in a narrower intra-category context. Implications for identity management strategies in minority groups are discussed.
\end{abstract}


The more, the merrier?

Numerical strength versus subgroup distinctiveness in minority groups

“The National Assembly of Québec recognizes that Quebecers wish to see the quality and influence of the French language assured, and is resolved therefore to make French the language of Government and the Law, as well as the normal and everyday language of work, instruction, communication, commerce and business." (Charter of the French language, S.Q., c. 5, 1977).

"Plaid Cymru the Party of Wales wants to see a fully bilingual nation, with each and every child given the opportunity to learn Welsh" (Plaid Cymru the Party of Wales manifesto, 2005).

Because minority groups are often low in power, their very distinctiveness may become a key source of meaning and value for their identity. For groups defined around an attribute that can be acquired, such as language, more people can in principle attain that attribute over time. However, we propose that increasing the number of those who have the prototypical attribute carries with it a threat to the distinctiveness of those who have had that attribute all along. In the present paper we test the proposition that prototypical members of minority groups may not always see increasing numerical strength as unequivocally positive, especially when their own position within the ingroup is made salient.

Consider the most salient example on the North American continent: French Canadians. Many French Canadians value their language very highly and feel threatened by the Anglophone culture that surrounds them (Bourhis, 1984; see also Bourhis \& Sachdev, 1984). If more Canadians spoke French, this would increase the numerical strength of French Canadians as a group and also help them to differentiate themselves from their more 
powerful English-speaking neighbors south of the border. However, within Canada this could also undermine the group distinctiveness of Francophones. We investigate such tensions and argue that, even in cases where a language is seen as identity-defining for a whole country (as is true of Welsh for Welsh speakers), large increases in how widely it is spoken might paradoxically be aversive, at least under certain conditions.

The low-power position of many minority groups means that their members can perceive threats to the distinctiveness or even existence of their ingroup identity (Jetten, Spears, \& Postmes, 2004). Such a threat often relates to the influence of a dominant, majority outgroup on the minority ingroup's distinctive characteristics, through pressure to assimilate with a majority group (Hornsey \& Hogg, 2000) or the majority group's adoption of the minority group's cultural symbols. Threats to distinctiveness are particularly acute when group members define their ingroup in terms of specific cultural attributes, such as language. Here, the hegemony of a dominant outgroup's culture means that minority group cultures face a perpetual struggle for recognition. There are many examples; as well as Francophones in Quebec, this applies to Basque and Catalan speakers in Spain, the Basques and Bretons in France, Welsh speakers in the UK, Native American languages in the USA, and Aboriginal and Maori cultures in Australia and New Zealand.

An important aspect of minority-majority relations in these contexts is that there is often variation in the extent to which category members have the attributes or characteristics that positively differentiate the minority group from the majority group. This is especially so in the case of large-scale categories such as gender, ethnicity, and nationality, in which particular characteristics are often promoted as category-defining by an active minority within the minority category (cf. Moscovici 1976) as part of a wider social and political agenda to influence minority-majority relations (Simon \& Klandermans, 2001). Note that our definition of a 'minority' here follows that offered by scholars such as Morris (1968), 
Tajfel (1978), and Wagely and Harris (1958). This definition emphasizes the importance of criteria such as power and status relations with a majority (i.e., dominant) outgroup rather than relative numerical size per se (Simon, Aufderheide, \& Kampmeier, 2001) - a definition that also maps onto group members' own conceptions of what defines majority and minority groups (Seyranian, Atuel, \& Crano, 2008). Having said this, numerical minorities also often tend to be less powerful than numerical majorities.

This raises interesting questions about how members of minority groups might react to changes in the prevalence of a potentially defining attribute or characteristic. A large and diverse body of research has demonstrated that when the distinctiveness of an ingroup category is questioned or threatened, ingroup members seek to re-establish ingroup distinctiveness by differentiating between the ingroup and outgroup on available dimensions of comparison (e.g., Brown, 1984a, 1984b; Hornsey \& Hogg, 2000; Jetten, Spears, \& Manstead, 1998, 2001; Jetten et al., 2004; Mummendey \& Schreiber, 1984). This can include attempts by active factions within the minority category to spread and strengthen 'distinctive' ingroup characteristics, such as attempts by members of minority ethnolinguistic groups to strengthen the ingroup language (i.e., give it vitality: Bourhis \& Giles, 1977; Giles, Bourhis, \& Taylor, 1977; Giles \& Johnson, 1981). Indeed, efforts to protect ingroup identity and language cover the full spectrum of collective action, from promotional campaigns, through political action and demonstrations, to occasionally illegal and even violent forms of direct action.

On the basis of the above evidence it seems reasonable to expect that any increase in the strength or prevalence of a 'distinctive' ingroup attribute (e.g., increased vitality of the ingroup language) would be valued by minority group members - and that the larger this increase, the more favorably it would be regarded. However, we suggest that for members of minority groups who already have that attribute, things might not be this straightforward. 
Although the prospect of a 'distinctive' attribute becoming more widespread within the ingroup would clearly strengthen the ingroup's position vis-à-vis the outgroup, it could also mean that the position of those who already have that attribute - and who may therefore have a distinct and prototypical position within the ingroup - is undermined. For example, as use of an ingroup language becomes more widespread, being able to speak it becomes less 'special,' perhaps diluting the identity claims of those who can speak the language. This is likely to be a particularly potent process in cases where an attribute is elevated in importance precisely because it is rare and difficult to attain, bolstering the 'special' claim over ingroup identity among those who have it (Coupland, Bishop, \& Garrett, 2003).

This prediction is consistent with two influential theories of inter-group relations, social identity theory (Tajfel \& Turner, 1979) and optimal distinctiveness theory (Brewer, 1991). Social identity theorists propose that groups try to differentiate themselves from others that are too similar to their own, thereby threatening their group's distinctiveness (Jetten et al., 2004). In optimal distinctiveness theory distinctiveness is more explicitly conceptualized in terms of (relative) group size; it is argued that minority groups simultaneously satisfy a need for assimilation and inclusion, and a contrasting need to differentiate self from others (see also Hornsey \& Jetten, 2004). Although the distinctiveness principles in both approaches are consistent with our predictions, the specific prediction we make here has not to our knowledge been made before. We propose that the distinctiveness motive may be sufficiently strong that it can lead those who have a 'distinctive' ingroup attribute to react negatively to the pervasive spread of that attribute within the ingroup category, even when that category is consensually defined by that attribute. This is because the spread of the attribute has the potential to undermine the distinctive group position of those within the broader ingroup category who already have the attribute. 
We test these predictions in two very different contexts. In Study 1, we establish a context in which female participants are assigned to a high emotional intelligence subgroup of women, and are led to believe that emotional intelligence is a characteristic that differentiates women as a whole from men (see Hacker, 1951, for a more in-depth consideration of women as a minority group). In Study 2, we examine a natural context by sampling from a prototypical subgroup (speakers of the Welsh language) within a minority category (the Welsh) in the UK. In both cases, we manipulate the prospective numerical strength of the 'distinctive' but rare attribute (high emotional intelligence in Study 1; Welsh language ability in Study 2) within the minority group, and gauge the affective reactions of members of the minority group who have this attribute. We present participants with one of three scenarios in which future prospects for the 'distinctive' attribute are described. These indicate that there will be little change in the prevalence of the 'distinctive' attribute in the future (it will be held by $25 \%$ of the ingroup category population), a moderate increase $(50 \%)$, or a large increase $(75 \%)$. In the little change condition, those who have the 'distinctive' attribute clearly remain in the negative position of being a minority within the ingroup, with low numerical strength. In the large increase condition, they face the prospect of greatly increased numerical strength, but also of becoming a clear majority within the ingroup, bringing the potential for their own subgroup distinctiveness to be undermined. In the moderate increase condition, they also stand to increase their numerical strength but crucially - in contrast to the large increase condition - without the prospect of becoming a (non-distinct) majority within the ingroup.

The role of comparative context

How should the concerns discussed above be reflected in affective reactions to these different prospects? In line with principles from self-categorization theory (Turner et al., 1987), one factor that is likely to shape affective reactions is the comparative context in 
which group members consider these prospects (David \& Turner, 1999; Haslam \& Turner, 1992; Haslam, Turner, Oakes, McGarty, \& Hayes, 1992). Specifically, does this inter-group context pit the inclusive ingroup category against a common outgroup, or does it focus on the ingroup category alone, such that divisions between those who do and do not have the 'distinctive' attribute become more apparent? It is important to note that, in line with selfcategorization theory (Turner et al., 1987), both of the salient contexts discussed here constitute intergroup contexts, albeit at different levels of inclusion. However, to distinguish the two contexts, we refer to them as the inter-category (or inter-group) context, and the intra-category (or intra-group) context, respectively.

Where the wider relationship between the ingroup and outgroup categories is salient (i.e., in an inter-category context), we predict that affective reactions are likely to become more positive as a function of the projected increase in the prevalence of the attribute. This is because in this context group members will focus on the needs of the ingroup as a whole in relation to the dominant outgroup, as opposed to their own subgroup's position within the ingroup category.

In contrast, where the relationship between those who do and those who do not have the attribute is made salient (i.e., in an intra-category context), participants should focus on their own (subgroup) position within the ingroup category. In this context, a large increase is likely to threaten the distinctiveness and exclusivity of their position within the ingroup as a whole. Consequently we expect that for a large increase, participants focused on the intracategory context will be considerably less positive towards this change than those for whom the inter-category context of ingroup versus outgroup is salient. In contrast, a moderate increase in the prevalence of the attribute will be regarded just as positively as in the intercategory context because, as discussed above, this condition offers the prospect of increased 
numerical strength while retaining an optimally-distinct position (neither a numerical minority nor a non-distinct majority) within the ingroup category.

Study 1

\section{Participants}

Participants were 198 British women with a mean age of 24.61 years $(S D=16.28)$.

They were randomly allocated by the survey software to one of the six conditions, resulting in cell sizes of between 25 and 40 .

Design

The study had a 3 (subgroup numerical strength: no increase, moderate increase, large increase) x 2 (context: intra-category vs. inter-category) between-subjects design. Materials and Procedure

The study was presented as an investigation into emotional intelligence among women, and consisted of a web-based questionnaire. Participants indicated their informed consent by clicking on an 'agree' button on a survey landing page. On doing so, participants were directed to the first page of the questionnaire.

Emotional intelligence questionnaire. The first page of the questionnaire contained a bogus emotional intelligence questionnaire. This consisted of 15 items on which participants indicated their agreement or disagreement with statements such as "When I see someone I know, I can usually tell how they are feeling," and "When someone I care about is sad, I feel sad too;" and 10 word-association items on which participants were presented with a target word (e.g., house) and had to select one of four other words (e.g., street; flat; room; home) that they most strongly associated with the target word.

After completing the questionnaire and clicking on the 'next page' button, participants were presented with a page that purportedly contained the results of the 
emotional intelligence test. In reality, all participants received feedback that they were high in emotional intelligence.

In order to position participants as part of a prototypical minority subgroup, the feedback also emphasized that emotional intelligence was a defining characteristic for women, but that women who were high in emotional intelligence were actually a minority of around $25 \%$ of women as a whole.

Context manipulation. The next page of the questionnaire contained the manipulation of comparative context. In the inter-category context condition, the page was headed by images of three female figures and three male figures. Explanatory text stated that "We are interested in what you, as a high EI woman, consider to be the distinguishing characteristics of women and men." Participants were instructed to provide up to three distinguishing characteristics of women in a box headed 'women,' and three distinguishing characteristics of men in a box headed 'men.' In the intra-category context condition, the page was headed by an image of three female figures only. Accompanying text explained that "We are interested in what you, as a high EI woman, consider to be the distinguishing characteristics of high EI women and low EI women." Participants were instructed to provide up to three distinguishing characteristics of high EI women in a box headed 'high EI women,' and three distinguishing characteristics of low EI women in a box headed 'low EI women.' In order to sustain the effect of the manipulation, each subsequent page of the questionnaire was headed by the images of the condition-appropriate female or female and male figures.

Future prospects for numerical strength manipulation. The manipulation of future prospects for subgroup numerical strength consisted of an article and graphs that described likely future trends for emotional intelligence among women. The conclusion of these was that women high in emotional intelligence would account for $25 \%$ (no increase condition), 
$50 \%$ (moderate increase condition), or $75 \%$ (large increase condition) of women as a whole by the year 2031. In each condition, the article began with the following description of the current level of emotional intelligence among women:

As indicated before, emotional intelligence is for many people at the heart of what it means to be a Woman, although current estimates suggest that high EI women make up only a small minority of around $25 \%$ of women as a whole.

The value and importance of emotional intelligence has been receiving renewed attention recently. This is because of the great increase in Women's participation in activities and access to resources (e.g., self-improvement books and courses, internet networking resources, lifestyle training) that have the potential to improve emotional intelligence. A key question is therefore whether emotional intelligence could become more widespread among Women as a whole.

The article then described the future prospects for numbers of high EI women,

followed by an illustrative graph. In the no increase condition, the article read:

The graph below shows that the projected number of EI women over the next 20 years is likely to show hardly any increase from what it is today, with no more than $25 \%$ of women falling into the high EI category. Despite the increased esteem and importance of emotional intelligence, it is most unlikely that the next few decades will see an increase in EI amongst Women.

In the moderate increase condition, the article read:

The graph below shows that the projected number of EI women over the next 20 years is likely to show a marked increase from what it is today, with up to $50 \%$ of women falling into the high EI category. With the increased esteem and importance of emotional intelligence, the next few decades could see an increase in EI amongst Women.

In the large increase condition, the article read:

The graph below shows that the projected number of EI women over the next 20 years is likely to show a dramatic increase from what it is today, with anything up to $75 \%$ of women falling into the high EI category. With the increased esteem and importance of emotional intelligence, the next few decades could see an increase in EI amongst Women.

The future prospects manipulation was checked using two items. The first item asked whether, according to the article, the number of women high in emotional intelligence was 
likely to increase, decrease, or stay the same. Participants responded on a 7-point scale ranging from -3 (decrease strongly) through 0 (stay the same) to 3 (increase strongly). The second item asked what the proportion of women high in emotional intelligence would be in the year 2031 according to the trends described in the article. Participants responded to this item by clicking one of three options: same as now; up to 50\%; up to $75 \%$.

Eight items measured emotional reactions to the future prospects for subgroup numerical strength $(\alpha=.963)$. Participants were asked to indicate on a 7-point scale ranging from -3 (completely disagree) to +3 (completely agree) whether these future prospects made them feel delighted; pleased; relieved; happy; content; proud; elated; positive.

After completing the questionnaire, participants were directed to a debriefing page in which they were fully debriefed and thanked for their participation.

Results

Manipulation check. A 3 (future prospects for numerical strength: no change; moderate increase; large increase) X 2 (comparative context: inter-category vs. intracategory) ANOVA on the future prospects for numerical strength manipulation check revealed only a main effect of the future prospects for numerical strength manipulation, $F(2$, $192)=29.96, p<.001, \eta_{\mathrm{p}}{ }^{2}=.240$ (other $F$ 's $<1.33$ ). Pairwise comparisons confirmed that, compared to the no increase condition $(M=0.44, S D=0.98)$, future prospects for emotional intelligence were seen as greater in the moderate increase condition $(M=1.96, S D=1.24), p$ $<.001$, and in the large increase condition $(M=1.99, S D=1.39), p<.001$. The difference between the moderate increase and large increase conditions was not significant, $F<1$.

The second future prospects manipulation check also confirmed that $85.5 \%, 91.4 \%$, and $90.4 \%$ of participants selected the correct option in the no, moderate, and large increase conditions, respectively ${ }^{1}$. Together, results on these checks suggest that the manipulation was successful. 


\section{Positive affect}

A similar ANOVA on the affect scale revealed a significant main effect of future prospects for numerical strength, $F(2,191)=14.40, p<.001, \eta_{\mathrm{p}}^{2}=.131(F<1$ for comparative context main effect). This was qualified by the expected interaction between the two factors, $F(2,191)=3.81, p=.024, \eta_{\mathrm{p}}{ }^{2}=.038$. This interaction is illustrated in the top panel of Figure 1. Simple effects analyses confirmed that the prospect of a moderate increase resulted in more positive affect than the prospect of no increase in both the intra-category and inter-category conditions, $F(1,191)=6.20, p=.014, \eta_{\mathrm{p}}^{2}=.031$, and $F(1,191)=22.92$, $p<.001, \eta_{\mathrm{p}}^{2}=.107$, respectively. Consistent with our main hypothesis, the simple main effect of context was significant only in the large increase condition, $F(1,191)=6.32, p=$ $.013, \eta_{\mathrm{p}}{ }^{2}=.032(p=.144$ in the no increase, and .601 in the moderate increase conditions). Specifically, positive affect was lower in the intra-category condition than in the intercategory condition.

\section{Discussion}

The results of this study provide good support for our hypotheses. They confirm that prospects of a moderate increase in the numerical strength of a 'distinctive' but rare ingroup attribute evoked significantly greater positive affect than the prospect of no increase, regardless of whether the context was intra-category or inter-category. However when a large increase was projected a quite different pattern emerged as a function of context. Specifically, the prospect of a large increase was greeted with less positive affect in the intracategory context than in the inter-category context. This supports our contention that while activists within minority groups may frequently base campaigns around strengthening the 'distinctive' characteristics that differentiate the ingroup from a comparison outgroup, increases in the numerical strength of such attributes may not always been seen as 
unequivocally positive - not least of all from the perspective of those who already have those attributes.

Our aim in Study 2 is to build upon these findings by implementing three specific refinements to the design of Study 1. First, affective reactions in Study 1 were measured solely in terms of positive emotions. This leaves open the possibility that affective reactions scores reflected affective arousal, rather than a specific and meaningful positive reaction. To address this possibility, we included negative as well as positive affect items in Study 2.

Second, our hypothesis suggests that the equivocal reaction to the prospect of a large increase in the intra-category condition is in part driven by perceptions that this increase may undermine the identity or special position of the 'prototypical' subgroup that already has the 'distinctive' attribute. In Study 2, we therefore measured the appraisal that the identity of the prototypical subgroup would be undermined in the case where the numerical strength of the 'distinctive' attribute was projected to grow sharply, and examined the mediating role of this appraisal. Third, our hypothesis would benefit from being tested it in a natural context in order to supplement the relatively contrived context examined in Study 1. To this end, in Study 2 we tested our hypothesis by sampling Welsh language speakers in Wales, UK. This is a context in which struggles over the strength of a numerically weak but prototypical characteristic are very real and passionate, and are linked to political campaigns and even to support for radical and illegal forms of social action (Livingstone, Spears, Manstead, \& Bruder, 2009b).

\section{Study 2}

The role of the Welsh language has historically been a controversial issue (Davis, 1994). Although only approximately $25 \%$ of the population of Wales can speak it, the Welsh language is widely accepted as a defining dimension of Welsh identity by Welsh-speaking and non-Welsh speaking Welsh people alike (Welsh Language Board, 2003). Welsh 
speakers in Wales provide a critical test-case, because of the identity-defining nature of the Welsh language for Welsh identity (accepted by non-speakers as well as speakers; see Coupland, Bishop, Williams, Evans, \& Garrett, 2005; Bourhis, Giles, \& Tajfel, 1973; Giles, Taylor, \& Bourhis, 1977; Livingstone, Spears, \& Manstead., 2009a), and the efforts being made to defend and expand the language after centuries of discrimination by the English. Building on the design of Study 1, we presented Welsh-speaking participants with one of three scenarios in which future prospects for Welsh were described. These indicated that there would be little change in the use of Welsh in the future (it would be spoken by $25 \%$ of the population), a moderate increase (50\%), or a large increase $(75 \%)$. We also manipulated the comparative context (intra-national vs. inter-national).

In terms of affective reactions, we expected to replicate the pattern observed in Study 1. In addition, we expected the equivocal response to a large increase in the intra-national context to be evident in specific appraisals of how such a change would undermine the position of Welsh speakers in Wales.

\section{Method}

\section{Participants}

Participants were 163 adults who defined themselves as Welsh speakers. They were randomly allocated by the survey software to one of the six conditions, resulting in cell sizes of between 10 and $33^{2}$. Gender and age information were not recorded.

Design

The study had a 3 (future prospects for ingroup language use: no increase, moderate increase, large increase) x 2 (context: intra-national vs. inter-national) between-subjects design. 


\section{Materials and Procedure}

The study consisted of a web-based questionnaire. Participants indicated their informed consent by clicking on an 'agree' button on a survey landing page. On doing so, participants were directed to the first page of the questionnaire.

Context manipulation. The first page of the questionnaire contained the manipulation of context. In the international context condition, the page was headed by images of Welsh, English, and UK flags alongside each other. Explanatory text stated that "We are interested in what you, as a Welsh person, consider to be the distinguishing characteristics of Welsh people and English people." Participants were instructed to provide up to three distinguishing characteristics of Welsh people in a box headed 'Welsh people,' and three distinguishing characteristics of English people in a box headed 'English people.' In the intra-national context condition, the page was headed by an image of the Welsh flag only. Explanatory text stated that "We are interested in what you, as a Welsh speaker, consider to be the distinguishing characteristics of Welsh people who speak Welsh and Welsh people who do not speak Welsh.” Participants were instructed to provide up to three distinguishing characteristics of Welsh-speaking people in a box headed 'Welsh-speaking Welsh people,' and three distinguishing characteristics of non-Welsh-speaking Welsh people in a box headed 'non-Welsh-speaking Welsh people.' In order to sustain the effect of the manipulation, each subsequent page of the questionnaire was headed by the images of the condition-appropriate national flags.

Future prospects for ingroup language use manipulation. The manipulation of future prospects for ingroup language use consisted of an article and graphs that described likely future trends for ingroup language use. The conclusion of these was that efforts to spread the use of the ingroup language would result in 25\% (no increase condition), 50\% (moderate increase condition) or $75 \%$ (large increase condition) of the ingroup population being able to 
speak the ingroup language. In each condition, the article began with the following description of the current level of ingroup language use:

The Welsh language is at the heart of Welsh national identity for many people, and has been so for a very long time. This is despite the grave threats it has faced down the centuries. At various points, the language stood on the brink of extinction. However, since the 1950's the language began to regain some of its lost status. This has been reflected in - and helped by - legislation such as the Welsh Language Acts of 1967 and 1993 that has removed the official stigma formerly placed upon the language.

One major indicator of the vitality of the Welsh language is of course the number of Welsh speakers in Wales. After a long period of decline, the number of people in Wales who could speak Welsh has recently been low but steady, at around $20 \%$ of the population. A key question has therefore been whether Welsh use could become more widespread across Wales as a whole. The article then described the future prospects for ingroup language use, followed by an illustrative graph. In the no increase condition, the article read:

The graph below shows that the projected number of Welsh speakers in Wales over the next 40 years is likely to show hardly any increase from what it is today, with no more than $25 \%$ of the Welsh population being able to speak Welsh. Despite the increased esteem and prestige of the language, it is most unlikely that the $21^{\text {st }}$ century will see an increase in Welsh speaking as dramatic as its decline in the $20^{\text {th }}$ century.

In the moderate increase condition, the article read:

The graph below shows that the projected number of Welsh speakers in Wales over the next 40 years is likely to show an increase from what it is today, with anything up to $50 \%$ of the Welsh population being able to speak Welsh. With the increased esteem and prestige of the language, the $21^{\text {st }}$ century should see an increase in Welsh speaking, although not as dramatic as its decline in the $20^{\text {th }}$ century.

In the large increase condition, the article read:

The graph below shows that the projected number of Welsh speakers in Wales over the next 40 years is likely to show a dramatic increase from what it is today, with anything up to $75 \%$ of the Welsh population being able to speak Welsh. With the increased esteem and prestige of the language, the $21^{\text {st }}$ 
century could see an increase in Welsh speaking that is just as dramatic as its decline in the $20^{\text {th }}$ century.

The future prospects manipulation was checked using two items. The first item asked whether, according to the article, the number of Welsh speakers in Wales was likely to increase, decrease, or stay the same. Participants responded on a 7-point scale ranging from -3 (decrease strongly) through 0 (stay the same) to 3 (increase strongly). The second item asked what the number of Welsh speakers in Wales would be in 2041 according to the trends described in the article. Participants responded to this item by clicking one of three options: same as now; up to $50 \%$; up to $75 \%$.

Fourteen items measured emotional reactions to the future language use information $(\alpha=.973)$. These included eight positive emotion items (delighted; pleased; relieved; happy; content; proud; elated; positive) and six negative emotion items (uneasy; angry, irritated; annoyed; bitter; negative). Responses were made on a 7-point scale ranging from 3 (completely disagree) to +3 (completely agree), and responses on the negative emotion items were reverse-scored before the scale mean was calculated ${ }^{2}$.

Next came a 4-item scale measuring the extent to which the future language use information was perceived as undermining the position of Welsh speakers in Wales $(\alpha=$ .671). The scale contained the items, 'Any special importance of Welsh speakers in Wales would be undermined;' 'Part of my identity would be undermined;' 'My identity would be enhanced' (reverse-scored); 'Any special importance of Welsh speakers in Wales would be enhanced' (reverse-scored). Participants responded on a 7-point scale ranging from -3 (completely disagree) to +3 (completely agree).

After completing the questionnaire, participants were directed to a debriefing page in which they were fully debriefed and thanked for their participation. 
Results

\section{Manipulation checks}

To check the effectiveness of the future prospects for ingroup language use manipulation, we submitted the first manipulation check item to a 3 (future prospects for ingroup language use: no increase, moderate increase, large increase) x 2 (context: intranational vs. inter-national) factorial ANOVA. This revealed only the expected main effect of future prospects for ingroup language use, $F(2,157)=23.71, p<.001, \eta_{\mathrm{p}}^{2}=.232$. Pairwise comparisons confirmed that, compared to the no increase condition $(M=0.51, S D=1.14)$, prospects for increased ingroup language use were seen as greater in the moderate increase condition $(M=1.78, S D=1.26), F(1,157)=29.82, p<.001, \eta_{\mathrm{p}}^{2}=.160$, and in the large increase condition $(M=2.12, S D=1.40), F(1,157)=37.28, p<.001, \eta^{2}=.192$. The difference between the moderate increase and large increase conditions was also marginally significant, $F(1,157)=2.89, p=.091, \eta_{p}^{2}=.018$.

The second ingroup language prospects manipulation check also confirmed that $75 \%$, $90 \%$, and $78 \%$ of participants selected the correct option in the no, moderate, and large increase conditions, respectively ${ }^{3}$. Together, results on these checks suggest that the manipulation was successful.

\section{Affective reaction}

A similar ANOVA on the affective reaction scale revealed significant main effects of future prospects for ingroup language use, $F(2,157)=138.37, p<.001, \eta^{2}{ }_{p}=.638$, and of context, $F(1,157)=16.13, p<.001, \eta_{\mathrm{p}}^{2}=.093$. These were qualified by the predicted interaction between the two factors, $F(2,157)=9.65, p<.001, \eta^{2}{ }_{p}=.109$. This interaction is illustrated in Figure 2. Simple effects analyses confirmed that the prospect of a moderate increase resulted in more positive affect than the prospect of no increase in both the intranational and inter-national conditions, $F(1,157)=124.08, p<.001, \eta_{\mathrm{p}}^{2}=.441$, and $F(1$, 
$157)=142.33, p<.001, \eta_{p}^{2}=.475$, respectively. Consistent with our main hypothesis, the simple main effect of context was significant only in the large increase condition, $F(1,157)$ $=26.70, p<.001, \eta_{\mathrm{p}}^{2}=.145(F \mathrm{~s}<1$ in the no increase and moderate increase conditions $)$. Specifically, positive affect was lower in the intra-national condition than in the international condition.

Welsh speakers' position undermined

A similar ANOVA on the appraisal of whether the position of Welsh speakers would be undermined revealed a significant main effect of future prospects for ingroup language use, $F(2,157)=11.59, p<.001, \eta^{2}=.129$, qualified by an interaction between future prospects for ingroup language use and context, $F(2,157)=3.96, p=.021, \eta_{\mathrm{p}}^{2}=.021$. This interaction is illustrated in the lower panel of Figure 2. Simple effects analysis confirmed that the main effect of context was significant in the large increase condition, $F(1,157)=$ $8.74, p=.004, \eta_{\mathrm{p}}^{2}=.053\left(F^{\prime} \mathrm{s}<1\right.$ in the no increase condition and moderate increase condition). Specifically, the position of Welsh speakers was felt to be undermined to a greater extent in the intra-national condition than in the inter-national condition.

\section{Relation between appraisals and affect}

In order to test whether the appraisal of subgroup identity being undermined mediated the effect of comparative context on affective reaction, we set up a multi-group path model using AMOS 7 in which the direct and indirect (through the 'identity undermined' appraisal) effects of context on affective reaction were tested. The paths from comparative context to appraisal and affective reaction were free to vary in strength across future prospects for numerical strength conditions, reflecting the interactions described above. The path from appraisal to affective reaction did not differ in strength across future prospects for numerical strength conditions $\left(\Delta \chi^{2}{ }_{2}=2.98, p=.225\right)$, and so was constrained across these conditions. 
The results of this path analysis are illustrated in Figure 3. Consistent with partial mediation, the path from comparative context to affective reaction in the large increase condition was reduced from $\beta=.474, p<.001$ to $\beta=.426, p=.003$ when the appraisal was entered into the model. Using 5000 bootstrap samples, the indirect effect of comparative context on affective reaction through appraisal was also found to be significant in the large increase condition, $b=.213 \mathrm{se}=.113 ; p=.029$ (95\% CI: .022, .456$)$.

\section{Discussion}

Results of Study 2 replicate and extend those of Study 1 . They confirm that prospects of a moderate increase produced significantly greater positive affect than the prospect of no increase in both intra-national and inter-national contexts. However when a large increase was projected a quite different pattern emerged as a function of context. Specifically, the prospect of a large increase was greeted with a less positive affective reaction in the intranational than in the inter-national context.

Correspondingly, the prospect of a large increase in Welsh language use increased the extent to which Welsh speakers' position would be undermined in the intra-national condition compared to the inter-national condition. Moreover, this specific appraisal in turn partially mediated the effect of comparative context on affective reactions in the large increase condition, indicating that affective responses to the future prospects for the language are at least in part explained by what participants thought that these prospects would mean for their own position within the ingroup. That this was partial rather than full mediation probably reflects the way in which affective reactions to prospects for an ingroup's future are determined by multiple appraisals. As other research has shown, these prospects for the ingroup's wider intergroup position are also likely to relate to perceptions of entitlement/legitimacy (Ellemers et al., 1993; Van Zomeren et al., 2008), efficacy (Van Zomeren et al., 2004), and identity threat (Branscombe et al., 1999; Livingstone et al., 
2009b). Implications for the position of one's own subgroup within the ingroup is therefore one among several factors that influence one's reaction to future prospects for the numerical strength of a 'distinctive' attribute within in a minority ingroup. Crucially though - and unlike the other appraisals mentioned above - this tension between the inter-category and intra-category implications of changes in numerical strength has not to our knowledge been considered as a contributing factor to minority group members' reactions to future prospects for the minority category.

\section{General Discussion}

For members of minority groups, the cultural characteristics that define the ingroup can be both highly important and vulnerable. This is particularly so when only a minority within the ingroup have access to them. It might therefore seem reasonable to expect that the prospect of these characteristics becoming more widespread within the ingroup would be seen as a good thing by ingroup members. Accordingly, minority-majority relations are often characterized by struggles for cultural recognition and protection on the part of minority group members, including campaigns aimed at revitalizing or establishing 'distinct' cultural or group-defining attributes (Giles et al., 1977; Giles \& Johnson, 1981).

However, the prospect of increases in the numerical strength of a 'distinctive' attribute may also be disadvantageous for those who possess it already. Although such increases may enhance ingroup identity in relation to an outgroup, it may undermine the relatively 'special' position occupied by those within the ingroup who already have that attribute. The latter should be particularly true when the attribute becomes so widespread that it is a majority attribute within the group and thereby offers little opportunity for positive distinctiveness within the ingroup (cf. Spears, Ellemers \& Doosje, 2009). 
Inter-category vs. intra-category distinctiveness: A dilemma for minority group members?

Together, the findings of the present studies support our hypothesis that strengthening ingroup identity may be something of a double-edged sword for minority group members who already have an attribute that is 'distinctive' for the minority category, but is not necessarily widespread within it. This is because it involves balancing two important psychological concerns; namely, the distinctiveness and strength of the minority group identity in an inter-category context, and their own distinctiveness in an intra-category context. As the present findings indicate, increasing the numerical strength of the minority group's defining attributes in this way is most likely to be viewed positively when there is a focus on the wider inter-category context. In contrast, a focus on intra-category relations is likely to mean that the spread of 'distinctive' characteristics will be viewed in a rather more ambivalent manner.

The contextual contingency evident here is consistent with self-categorization principles (Turner et al., 1987), in which comparative context shifts the self-focus from group to subgroup. It is also consistent with optimal distinctiveness theory (Brewer, 1991), insofar as minority groups satisfy both inclusion and differentiation needs. In the present case our context manipulation simply shifts which self-category of our participants forms the minority group (i.e., being Female or an emotionally intelligent Female in Study 1; being Welsh or being a Welsh speaker in Study 2). The present research nevertheless extends previous empirical research on minority groups, by showing that the presumed desire to strengthen group-defining properties such as a language can be equivocal, depending on social context. These findings also help to make a broader theoretical point that distinguishes our approach from others that emphasize how identifying with a minority subgroup can help to satisfy distinctiveness needs (e.g., Hornsey \& Jetten, 2004). Specifically, we suggest that the value of being part of distinctive subgroup within a minority is not a fixed property of the 
subgroup's relative size. Rather, the 'value' of being a distinctive subgroup - and of changes in that distinctiveness - depends on the shifting intergroup context, both in terms of the salient frame of reference (Turner et al., 1987), and the wider power and cultural relationships within which the minority category is embedded.

The present findings also have clear relevance for a wide range of settings in which inter-group relations are characterized by struggles over the valued symbols and attributes of a minority group identity. This relevance is most direct in relation to campaigns by members of minority groups to protect and extend a vulnerable group attribute such as language or different cultural practices. These campaigns are often targeted as much at other members of the minority category as they are at a majority outgroup. The intention is to raise consciousness of 'distinctive' features of and practices within the minority category and ensure that they live on. These campaigns are, in turn, often an important feature of struggles to achieve social, economic and political equality (Tajfel, 1978). Our findings speak to the psychological factors that can work for or against social and political campaigns to strengthen a minority group identity in this way. A key implication here is that policy makers and campaigners need to be sensitive to the intra-category concerns of minority group members, as well as the inter-category position of the minority category as a whole. If the potential impact of identity-based campaigns on intra-group relations is ignored, then such campaigns may lose support from the very group members who already embody ingroup identity. Conversely, our approach suggests that support for identity-based campaigns is most likely when there is a clear focus on the 'bigger picture' of the ingroup's relation to a majority outgroup. Here, the increased vitality of ingroup identity is likely to be understood less as an intra-group threat, and more as an inter-group opportunity for equality and recognition. 


\section{Conclusion}

The present findings shed light on an important, but as yet un-researched aspect of minority-majority group relations. Although it may seem logical that members of minority groups who possess a group-defining attribute would view the prospect of strengthening ingroup identity in unequivocally positive terms, we have shown here that this is not always the case. Rather, the context in which such prospects are evaluated is crucial in determining whether strengthening ingroup identity is regarded as a valuable weapon in inter-group struggle, or as a double-edged sword that helps to divide and rule. 


\section{Footnotes}

${ }^{1}$ Removal of participants who failed this check did not change the outcome of any subsequent analyses. They were therefore retained in order to preserve randomness of allocation to condition.

${ }^{2}$ The software used in this study unexpectedly allocated fewer participants to the international, large increase condition $(N=10)$ than to other conditions (next smallest $N=26$ ). The consistency of the findings across both studies, the adherence of the data to distributional assumptions, and the use of Type III sums of squares together led us to conclude that although not ideal, this anomaly was ultimately inconsequential.

${ }^{3}$ Analysis of the negative affect items as a separate scale $(\alpha=.94)$ revealed effects that directly mirrored those on the positive affect items as a separate scale $(\alpha=.97)$. Moreover, the two scales were highly correlated $r=.771, p<.001$. Given that the effects on the separate scales were therefore unlikely to be independent, we chose to combine the positive and negative affect items into a single scale.

${ }^{4}$ Removal of participants who failed this check did not change the outcome of subsequent analyses, with the exception of the interaction on the Welsh speakers' position undermined measure, which was no longer significant, $F(2,128)=2.32, p=.102, \eta^{2}=.035$.

Nevertheless, the pattern of this interaction was identical, as were the results of simple effects analyses. Moreover, the effect size for this interaction was actually greater than that of the analysis reported in the main text $\left(\eta_{p}^{2}=.021\right)$, increasing our confidence that the effect of removing those who failed the check was simply due to a loss of power rather than a qualitative change in the results. All participants were therefore retained in order to preserve randomness of allocation to condition, and to avoid a potential Type II error. 


\section{References}

Bourhis, R. Y. (1984). Cross-cultural communication in Montreal: Two field studies since Bill 101. International Journal of the Sociology of Language, 46, 33-47.

Bourhis, R. Y, \& Sachdev, I. (1984). Vitality perceptions and language attitudes: Some Canadian data. Journal of Language and Social Psychology, 3, 97-126.

Bourhis, R. Y. \& Giles, H. (1977). The language of intergroup distinctiveness. In H. Giles (Ed.), Langauge, ethnicity and intergroup relations. London: Academic Press.

Bourhis, R. Y., Giles, H., \& Tajfel, H. (1973). Language as a determinant of Welsh identity. European Journal of Social Psychology, 3, 447-460.

Branscombe, N.R., Ellemers, N., Spears, R., \& Doosje, B. (1999). The context and content of social identity threat. In N. Ellemers, R. Spears \& B. Doosje (Eds.), Social identity: Context, commitment, content (pp. 35-58). Oxford, England: Blackwell.

Brewer, M. B. (1991). The social self: On being the same and different at the same time. Personality and Social Psychology Bulletin, 17, 475-482.

Brown, R. J. (1984a). The role of similarity in intergroup relations. In H. Tajfel (Ed.). The social dimension: European developments in social psychology (pp. 603-623). Cambridge: Cambridge University Press.

Brown, R. J. (1984b). The effects of intergroup similarity and cooperative versus competitive orientation on intergroup discrimination. British Journal of Social Psychology, 23, 21-33.

Coupland, N., Bishop, H., \& Garrett, P. (2003). Home truths: Globalistion and the iconising of Welsh in a Welsh-American newspaper. Jounral of Multilingual and Multiculutral Development, 24, 153-177.

Coupland, N., Bishop, H., Williams, A., Evans, B., \& Garrett, P. (2005). Affiliation, engagement, language use and vitality: Secondary school students' subjective 
orientations to Welsh and Welshness. The International Journal of Bilingual Education and Bilingualism, 8, 1-24.

David, B. \& Turner, J. C. (1999) Studies in self-categorization and minority conversion: The ingroup minority in intragroup and intergroup contexts. British Journal of Social Psychology, 38, 115-134.

Ellemers, N., Wilke, H., \& Van Knippenberg, A. (1993). Effects of the legitimacy of low group or individual status on individual and collective status-enhancement strategies. Journal of Personality and Social Psychology, 64, 766-778.

Giles, H., Bourhis, R., \& Taylor, D. M. (1977). Towards a theory of language in ethnic group relations. In H. Giles (Ed.), Langauge, ethnicity and intergroup relations. London: Academic Press.

Giles, H. \& Johnson, P. (1981). The role of language in ethnic group relations. In J.C. Turner \& H. Giles (Eds.), Intergroup behaviour. Oxford: Basil Blackwell.

Giles, H., Taylor, D. M., \& Bourhis, R. Y. (1977). Dimensions of Welsh identity. European Journal of Social Psychology, 7, 165-174.

Hacker, H. M. (1951). Women as a minority group. Social Forces, 30, 60-69.

Haslam, S. A., \& Turner, J. C. (1992). Context-dependent variation in social stereotyping 2: The relationship between frame of reference, self-categorization and accentuation. European Journal of Social Psychology, 22, 251-277.

Haslam, S. A., Turner, J. C., Oakes, P. J., McGarty, C., \& Hayes, B. K. (1992). Contextdependent variation in social stereotyping 1: The effects of intergroup relations as mediated by social change and frame of reference. European Journal of Social Psychology, 22, 3-20.

Hornsey, M. J., \& Hogg, M. A. (2000). Assimilation and diversity: An integrative model of subgroup relations. Personality and Social Psychology Review, 4, 143-156. 
Hornsey, M. J., \& Jetten, J. (2004). The individual within the group: Balancing the need to belong with the need to be different. Personality and Social Psychology Review, 8, 248-264.

Jetten, J., Spears, R., \& Manstead, A. S. R. (1998). Defining dimensions of distinctiveness: Group variability makes a difference to differentiation. Journal of Personality and Social Psychology, 74, 1481-1492.

Jetten, J., Spears, R., \& Manstead, A. S. R. (2001). Similarity as a source of discrimination: The role of group identification. European Journal of Social Psychology, 31, 621640.

Jetten, J., Spears, R., \& Postmes, T. (2004). Intergroup distinctiveness and differentiation: A meta-analytic integration. Journal of Personality and Social Psychology, 86, 862879.

Livingstone, A. G., Spears, R., \& Manstead, A. S. R. (2009a). The language of change? Characterisations of ingroup social position, threat, and the deployment of 'distinctive' group attributes. British Journal of Social Psychology, 48, 295-311.

Livingstone, A. G., Spears, R., Manstead, A. S. R., \& Bruder, M. (2009b). Illegitimacy and identity threat in (inter)action: Predicting intergroup orientations among minority group members. British Journal of Social Psychology, 48, 755-775.

Morris, H. S. (1968). Ethnic Groups. In D. L. Sills (Ed), International encyclopedia of the social sciences (Vol. 5). New York: Macmillan.

Moscovici, S. (1976). Social influence and social change. London: Academic Press.

Mummendey, A., \& Schreiber, H. (1984). Social comparison, similarity and ingroup favouritism: A replication. European Journal of Social Psychology, 14, 231-233. 
Simon, B., Aufderheide, B. and Kampmeier, C. (2001) The social psychology of minoritymajority relations. In R. Brown \& S. L. Gaertner (Eds), Blackwell Handbook of Social Psychology: Intergroup Processes. Oxford, UK: Blackwell Publishers Ltd.

Simon, B., \& Klandermans, B. (2001). Politicized collective identity: A social psychological analysis. American Psychologist, 56(4), 319-331.

Seyranian, V., Atuel, H., \& Crano, W. D. (2008). Dimensions of majority and minority groups. Group Processes Intergroup Relations, 11, 21-37.

Spears, R., Ellemers N., \& Doosje, B. (2009). Strength in numbers or less is more? A matter of opinion and a question of taste. Personality and Social Psychology Bulletin, 35, 1099-1111.

Tajfel, H. (1978). The social psychology of minorities. London: Minority Rights Group.

Tajfel, H., \& Turner, J. C. (1979). An integrative theory of intergroup conflict. In: W.G. Austin \& S. Worchel (Eds.), The social psychology of intergroup relations (pp. 3347). Monterey, CA: Brooks-Cole.

Turner, J. C., Hogg, M. A., Oakes, P. J., Reicher, S. D., \& Wetherell, M. S. (1987). Rediscovering the social group: A self-categorization theory. New York: Basil Blackwell.

Van Zomeren, M., Postmes, T., \& Spears, R., (2008). Toward an integrative social identity model of collective action: A quantitative research synthesis of three sociopsychological perspectives. Psychological Bulletin, 134, 504-535.

Van Zomeren, M., Spears, R., Fischer, A. H., \& Leach, C. (2004). Put your money where your mouth is! Explaining collective action tendencies through group-based anger and group efficacy. Journal of Personality and Social Psychology, 87, 649-664.

Wagley, C., \& Harris M. (1958). Minorities in the New World: Six case studies. New York: Columbia University Press. 
Figure captions

Figure 1. Interaction between future prospects for numerical strength and comparative context on affective reaction in Study 1. Error bars represent standard errors.

Figure 2. Interaction between future prospects for numerical strength and comparative context on affective reaction (upper panel) and appraisals of Welsh speakers' identity being enhanced (lower panel) in Study 2. Error bars represent standard errors.

Figure 3. Appraisal partially mediates the effect of comparative context on affective reaction in the large increase condition (Study 2). 
Figure 1

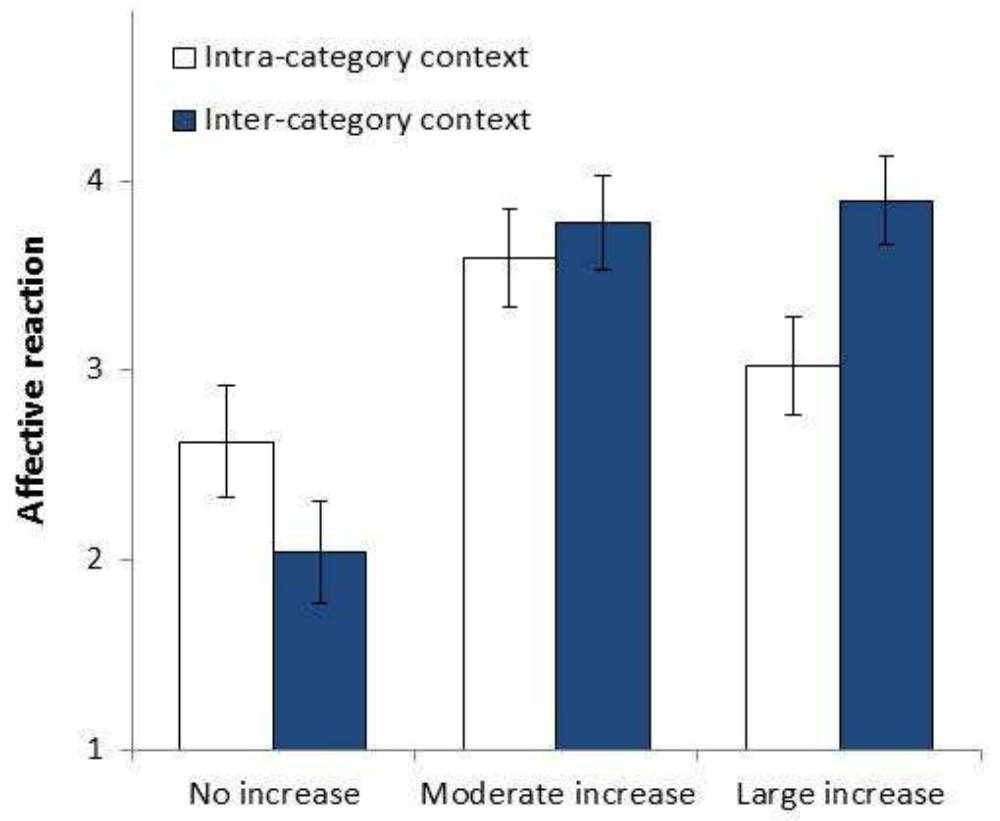

Future prospects for numerical strength 
Figure 2

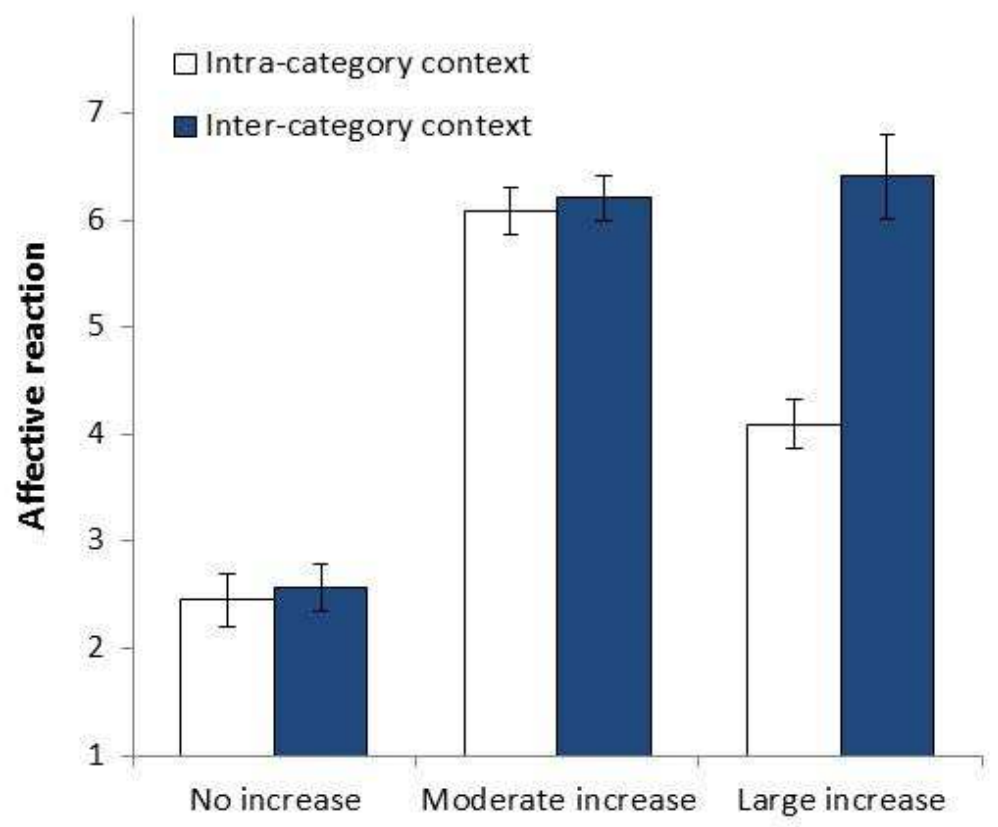

Future prospects for numerical strength

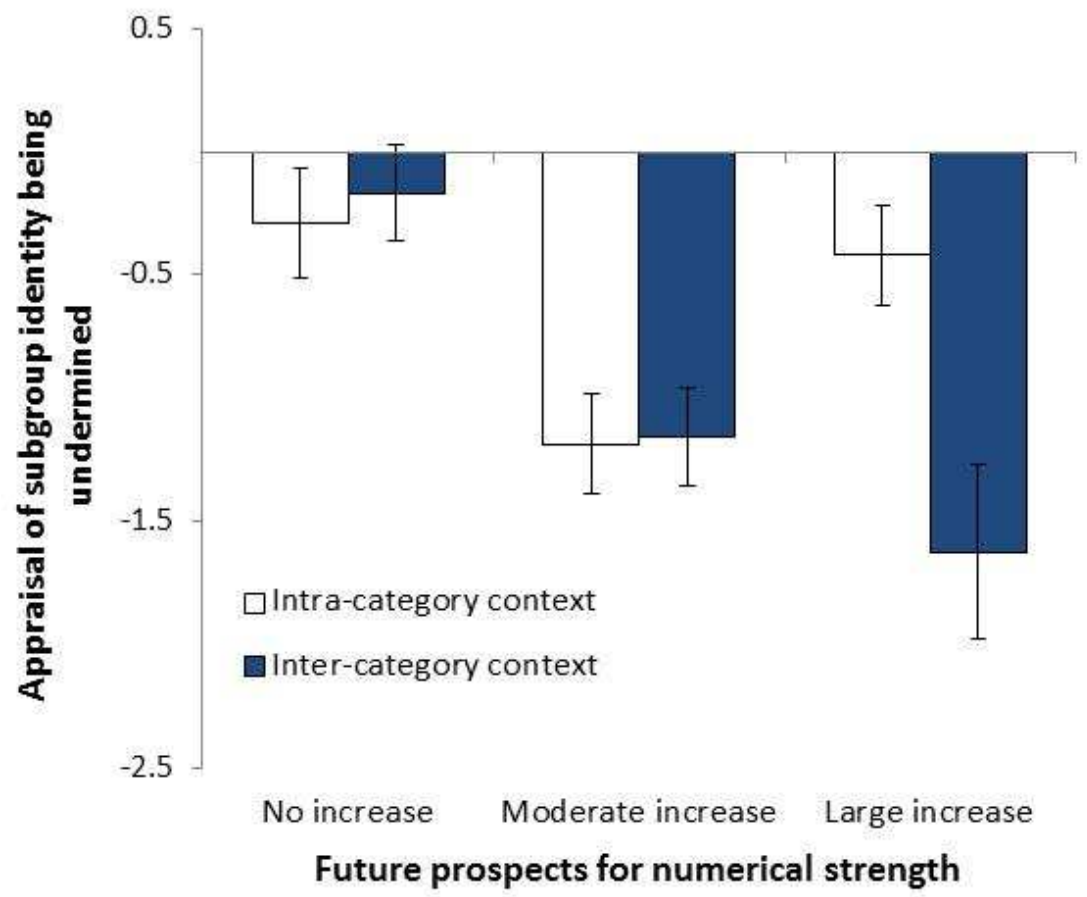


Figure 3

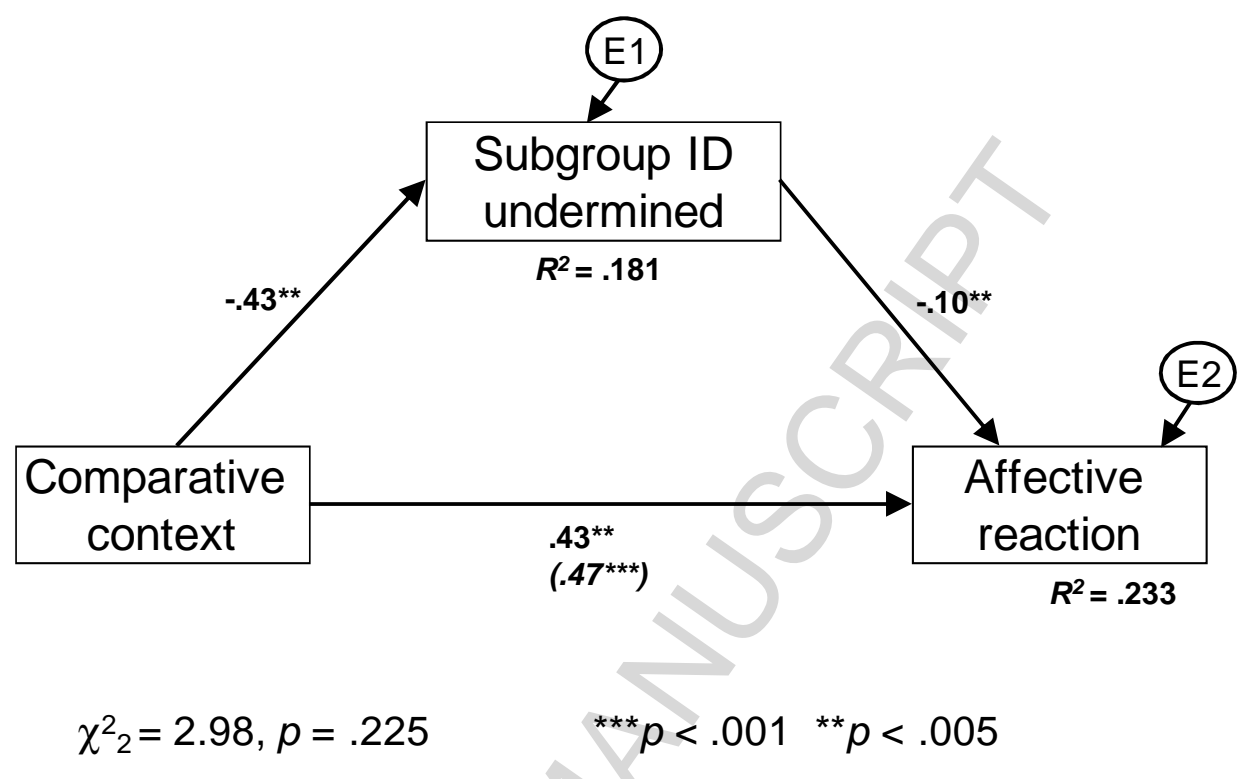

